\title{
Xenogenic bone matrix extracts induce osteoblastic differentiation of human bone marrow-derived mesenchymal stem cells
}

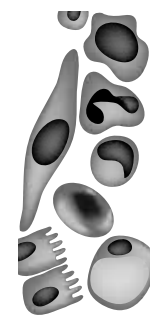

\author{
Marwan E El-Sabban*1, \\ H ilda El-Khoury', \\ Rima H amdan-Khali ${ }^{2}$, \\ Steen Sindet-Pedersen ${ }^{3}$ \& \\ Ali Bazarbachi*2† \\ ${ }^{\dagger}$ Author for correspondence \\ ${ }^{1} \mathrm{D}$ epartment of $\mathrm{H}$ uman \\ M orphology, Faculty of \\ M edicine, American \\ University of Beirut, \\ PO Box 113-0236, Beirut, \\ Lebanon \\ Tel.: +961 1350000 \\ ext. 4765; \\ Fax: +9611350000 \\ ext. 4913; \\ E-mail: me00@aub.edu.lb \\ ${ }^{2} \mathrm{D}$ epartment of Internal \\ M edicine, Faculty of \\ $M$ edicine, American \\ University of Beirut, \\ PO Box 11-6044, Beirut, \\ Lebanon \\ Tel.: +961 1350000 \\ ext. 4910; \\ Fax: +961 1350000 \\ ext. 4913; \\ E-mail: bazarbac@ \\ aub.edu.lb \\ ${ }^{3} \mathrm{~T}$ he L ondon Research \\ Company, London, U K
}

*Both authors contributed equally to this work

Keywords bone matrix, growth factors, osteoinduction, stem cells, tissue engineering

fitured ichen fiss

Colloss ${ }^{\circledR}$ and Colloss- $\mathrm{E}^{\circledR}$ are sterile acellular lyophilizates extracted from bovine and equine bone matrix, respectively. Animal and dinical studies have shown that these xenogenic bone matrix extracts (BMEs) are effective as bone graft substitutes. In this report, we investigated the effect of Colloss and Colloss-E on human adult in vitro-expanded bone marrow-derived mesenchymal stem cells (BM MSCs). Specifically, we assessed whether these xenogenic BMEs induced osteoblastic differentiation of cultured BMMSC. We show that BMM SCs treated with either Colloss or Colloss-E exhibited characteristic osteoblastic morphological changes accompanied by the expression of osteoblast-specific markers, such as alkaline phosphatase activity, osteopontin secretion and calcium deposits, explicitly demonstrating that these bone matrix extracts induce osteoblastic differentiation of BMM SCs in vitro. Hence, xenogenic BMEs induce bone-specific differentiation of BMMSCs, presumably through providing stem cells with structural and soluble mediators that mimic the in vivo microenvironment. These results may explain the in vivo mode of action of these medical devices, and potentially provide a novel tissue engineering-based treatment of bone defect, using autologous BMMSCs pretreated with BMEs.

Bone autografts remain the gold standard in reconstructive surgery for enhancing bone repair [1-3]. H owever, many factors, including limited availability of autografts, donor site morbidity and the need for a second operation site, emphasize the need for alternative approaches [4,5]. Allogenic demineralized bone matrix (DBM), bone substitutes and tissue engineering are emerging as credible alternatives. Banked allograft DBM are among the most commonly used osteoinductive graft materials in orthopedics and dentistry [6-9]. However, it is difficult to compare, in randomized prospective clinical trials, the efficacy of DBM to that of autologous bone, since most commercial tissue banks do not evaluate the extent of their D BM 's potential for bone formation [10]. A recent randomized trial comparing DBM with autograft showed relative equivalency between grafts in spinal fusion [11]. Additionally, allografts carry the risk of infectious disease transmission. Furthermore, in animal studies, allografts, when compared with autograft, exhibited slower fusion rate and enhanced graft resorption and infection rate. 0 steoinductive constructs generated by the production of biologically active scaffolds loaded with cells and/or growth factors, such as bone morphogenetic proteins (BM Ps), produce new bone that can be used to regenerate and close large bone defects [12-15]. BM Ps are the largest subgroup within the transforming growth factor (TGF)- $\beta$ superfamily, with diverse functions, essential for development and maintenance of many organ systems in addition to the skel eton [12]. Unfortunately, recombinant BM Ps are needed in high concentration to elicit function and are very expensive, which limits their clinical use and justifies the search for cost-effective alternatives. A potential alternative is the use of xenogeneic D BM . H owever, it is hypothesized that reported immunogenicity and nonviability of xenogeneic DBM results from lipids and plasma proteins not removed during typical demineralization processes [16].

An inexpensive alternative to recombinant growth factors, the medical device $\mathrm{Colloss}{ }^{\circledR}$, has demonstrated ability to stimulate new bone formation in vivo [17-22]. Colloss is a lyophilizate of bone proteins extracted from the extracellular matrix of bovine cortical diaphyseal bone. To overcome the potential risk of transmissible spongiform encephalopathy (TSE) infection, an equine-derived version, Colloss- ${ }^{\circledR}$, has been prepared [23]. According to the O ffice International des Epizooties, TSE has been reported in bovines, sheep, goats, cervids, farmed mink, domestic cats and exotic ungulates in zoos, but not in horses [24,25]. Colloss and Colloss-E provide a 3D framework or scaffold that supports ingrowth of blood vessels and bone-forming cells. These bone fillers are cotton-like lyophilizates in 
which the bone type I collagen is thought to act as a carrier matrix for noncollagenous proteins, such as native BM Ps [26]. Schlegel and colleagues measured elevated BM P-2 expression when Colloss was implanted into the bone void. It remains unclear if the evaluated levels are attributed to BM P release from surrounding cells [26].

In animal studies, Colloss and Colloss-E are effective in enhancing bone formation $[15,17-21,26,27]$. Both extracts were equally osteoinductive as autograft bone in animal spinal fusion or cortical bone defect models [21,23]. 0 wing to their structural biocompatibility, Colloss and Colloss-E are suitable matrices for cells to infiltrate, reside and produce bony in-growth across the graft site while completely resorbing within a few weeks. Clinically, Colloss is currently used as a filler for bone fractures, empty spaces in bone and gaps around dental implants.

Bone marrow-derived mesenchymal stem cells (BMMSCs) are infrequent multipotent cells that can differentiate into multiple lineages, such as bone, cartilage and muscle cells among others [29-32]. H ence, these cells are of potential clinical importance for the repair of damaged tissues. The local microenvironment in vivo is critical to support the desired differentiation of stem cells or to sustain the phenotype of the stem cell-derived in vitro differentiated cells. This local microenvironment comprises a physical support supplied by the organ matrix as well as tissue-specific cytokines. Bone matrix contains collagen type 1 and many of the growth factors involved in the cascade of bone formation [12]. Consequently, when bone marrow is used to enrich orthopedic grafting matrices, it almost invariably produces faster and more consistent defect healing compared with bone marrow or the carrier matrix alone [33].

In this report, we investigated the effect of Colloss and Colloss-E on adult in vitro expanded BM M SCs. Specifically, we assessed whether these xenogenic bone matrix extracts (BMEs) induced osteoblastic differentiation of cultured BM M SC S.

\section{Materials \& methods}

Preparation of Colloss ${ }^{\circledR} \&$ Colloss-E $^{\circledR}$

Bovine and equine bone protein extracts, Colloss and Colloss-E, respectively, were supplied by $O$ ssacur, AG (O berstenfeld, Germany). These extracts were prepared, aseptically, from cortical diaphysis of long bones from diseasefree, young ( $<12$ months old) calves and foals of closed herds. Briefly, bones were pulverized and delipidated with acetone for $60 \mathrm{~min}$ at $4^{\circ} \mathrm{C}$. The resulting bone particles were demineralized in $0.6 \mathrm{~N}$ hydrochloric acid for 60 min at $4^{\circ} \mathrm{C}$. Particles were then washed in deionized water, extracted with $4 M$ guanidine hydrochloride and ultrafiltered using $3 \mathrm{~K}$ nominal molecular weight cut-off membranes. Colloss and Colloss-E are normally supplied as sterile lyophilizates that comprise a suspension when reconstituted. H ence, Colloss and Colloss-E dispersion in water, an intermediate stage from the manufacturing procedure, was used for this study.

Cells, treatment $\&$ antibodies

Six different patients requiring bone marrow aspiration for routine follow-up of hematologic disorders, who had signed the informed consent, were recruited. All used bone marrow samples that were used exhibited normal morphology. This study was approved by the institutional review board (IRB) of the American University of Beirut, Lebanon.

H uman BM M SC $s$ were isolated from 3-4 ml of bone marrow aspirates using Ficoll density gradient (Ficoll-Paque ${ }^{\mathrm{TM}}$ Plus, Amersham Bioscience, UK). C ells were cultured in D ulbecco's modified Eagles medium (1000 mg/L-glucose/L, L-glutamine and sodium pyruvate; Sigma Aldrich, USA), with $1 \%$ penicllin/streptomycin, fetal bovine serum (Gibco BRL, USA) at $37^{\circ} \mathrm{C}$ in $95 \%$ air with $5 \%$ carbon dioxide at $100 \%$ humidity. M edium was replenished every 2 days. Confluent cultures were passaged by trypsinization and gentle scraping. Cells between passage five and seven were used for all experiments.

For the assessment of osteoblastic differentiation, $1.5 \times 10^{4}$ or $3 \times 10^{4}$ BM MSCs were seeded in 12- and six-well plates, respectively, and treated with 1:50 dilution of either Colloss or Colloss-E (28 and $32 \mu \mathrm{g} / \mathrm{ml}$, respectively). Morphological changes were documented by photo-microscopy on a daily basis. Cell proliferation was assessed using the CellTiter $96^{\circledR}$ (Promega, U SA). Expression of Stro- 1 and osteopontin was evaluated by fluorescence immunocytochemistry using specific antibodies ( $R \& D$ systems, USA).

\section{Alkaline phosphatase activity}

BM M SC S were treated for 7 or 14 days with medium containing 1:50 Colloss or Colloss-E (28 and $32 \mu \mathrm{g} / \mathrm{ml}$, respectively). Alkaline phosphatase protein levels in total cell lysates 
Figure 1. Bovine and equine bone extracts $\left(\mathrm{Colloss}^{\circledR}\right.$ and Colloss- ${ }^{\circledR}{ }^{\circledR}$ ) induce in vitro differentiation of BMMSCs.

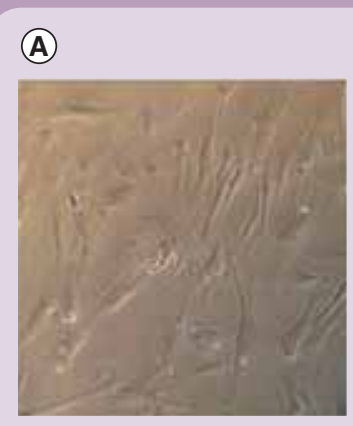

Control

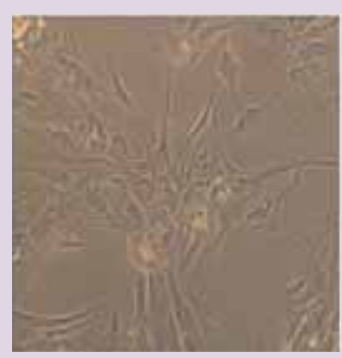

Equine

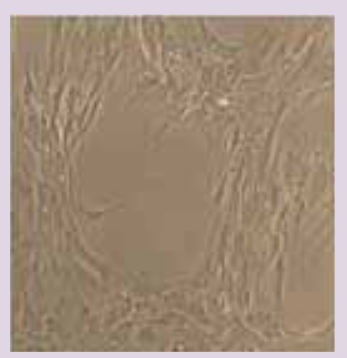

Bovine

(B)

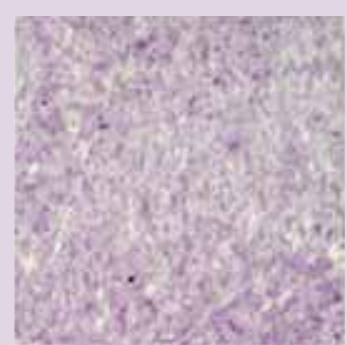

Control

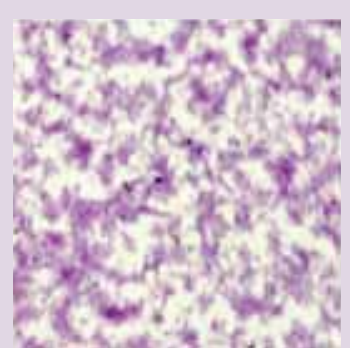

Equine

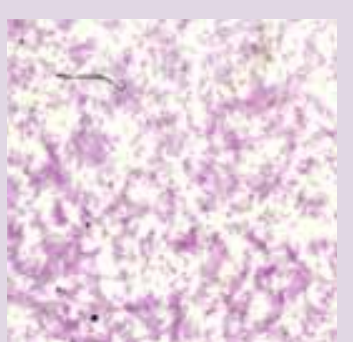

Bovine

(C)

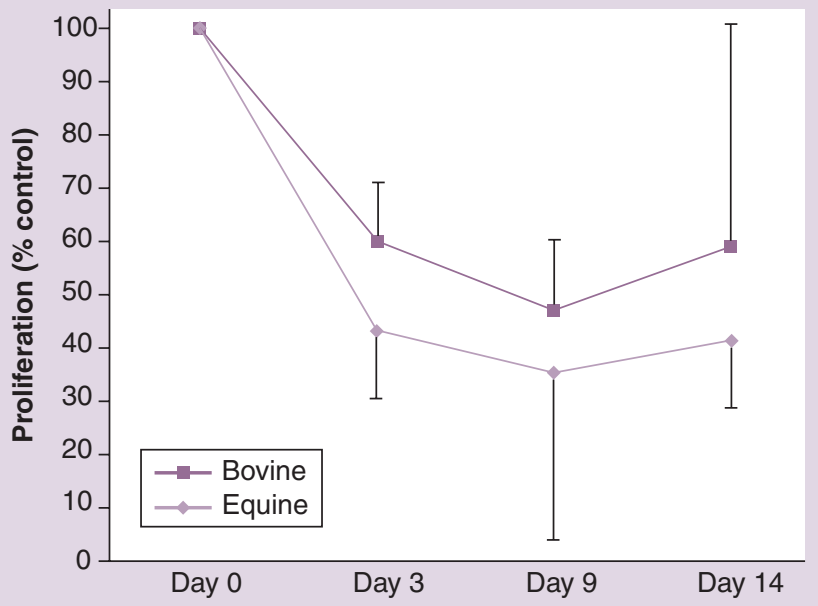

BM M SCs at passage six were treated with a 1:50 dilution of Colloss (bovine) or Colloss-E (equine) (28 and $32 \mu \mathrm{g} / \mathrm{ml}$, respectively) for different time points. (A) M orphological changes of BM M SCs induced by treatment with Colloss and Colloss-E for 7 days $(n=6)$. (B) Hematoxylin and eosin staining of the BM M SC cell culture after treatment with Colloss and Colloss-E for 15 days $(n=3)$. (C) Proliferation of BM M SC at different time intervals after treatment with Colloss and Colloss- $E(n=6)$.

were evaluated by western blot using specific antibodies (Abcam, UK). Alkaline phosphatase enzyme activity was assessed in medium-free cell lysates as described by 0 reffo and colleagues using $5 \mathrm{mM}$ of $\mathrm{p}$-nitrophenyl phosphate (Amresco, USA) as a substrate in 2-amino-2-methyl-1 propanol (Sigma) alkaline buffer solution [34]. 
Osteopontin secretion

BM M SC s were treated for 7, 14 and 30 days with medium containing Colloss or Colloss-E (28 and $32 \mu \mathrm{g} / \mathrm{ml}$, respectively). O steopontin levels were determined in cell-free supernatant using a human OPN TiterZyme ELISA kit (Assay designs, USA) as recommended by the manufacturer.

\section{Calcium deposits}

BM M SC $s$ were treated for 15 days with medium containing 1:50 Colloss or Colloss-E (28 and $32 \mu \mathrm{g} / \mathrm{ml}$, respectively). Cultures were stained with hematoxylin and eosin $(H \& E)$ and calcium deposits were counted.

\section{ELISA}

Protein levels of various osteogenic cytokines in Colloss-E were determined by ELISA (antibodies generated against human factors), according to the supplier's instructions. Levels of BM P-2,

\section{Figure 2. Colloss ${ }^{\circledR}$ and Colloss- $\mathrm{E}^{\circledR}$ induce alkaline phosphatase activity in BMMSCs.}

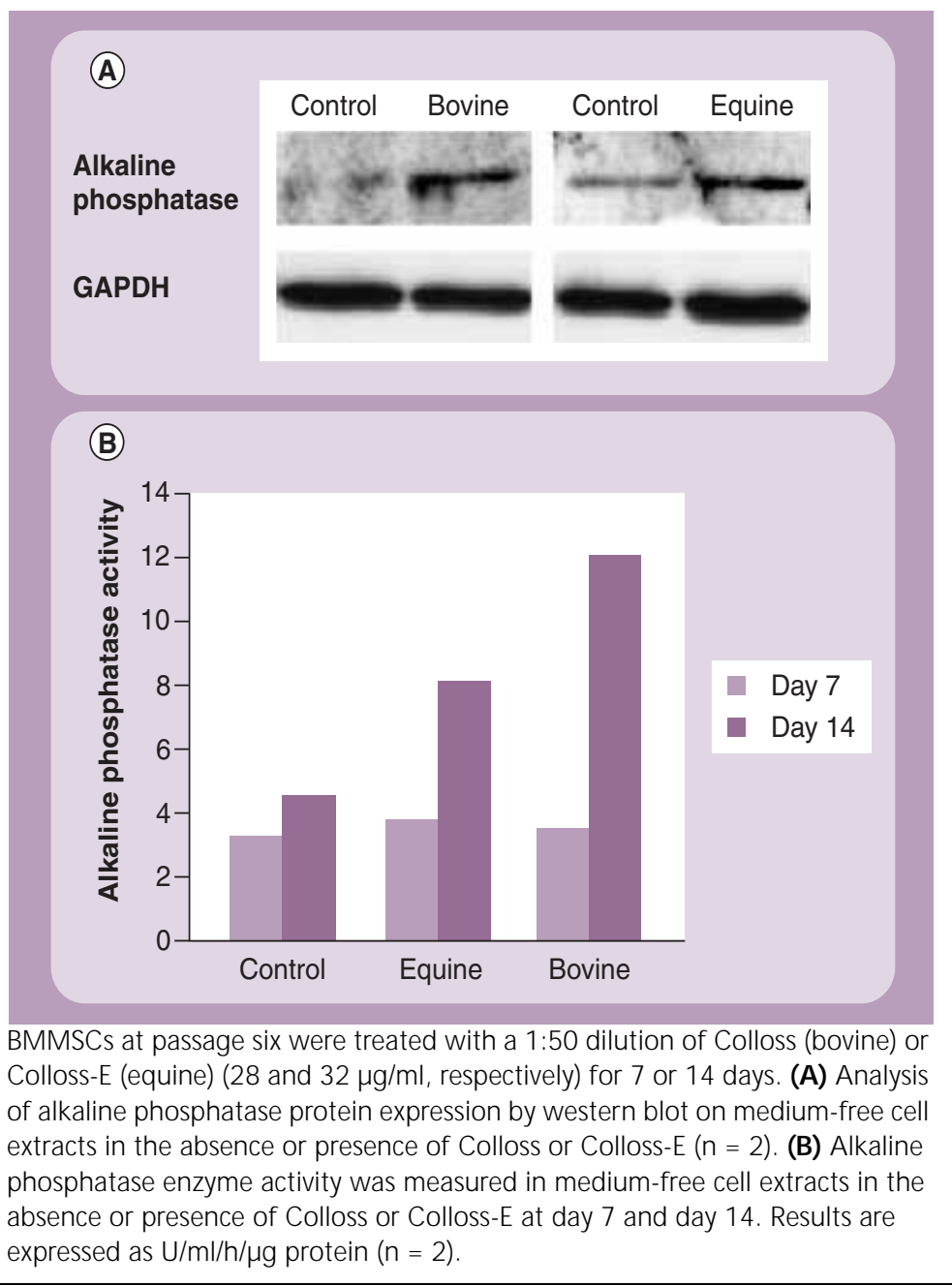

TFG $-\beta_{1}$ and insulin-like growth factor (IGF)-1 were measured using commercial ELISA kits from $R \& D$ Systems, whereas levels of BM P-7 were measured using commercial ELISA kits from RayBiotech.

\section{Statistics}

Statistical analysis was determined by analysis of varience (AN OVA) using SPSS for windows. The results are expressed as mean \pm standard error. p-values of 0.05 were considered significant.

\section{Results}

Bovine \& equine BMEs induce morphological changes of BMMSC

BMMSC cultured at passage six exhibited a characteristic elongated morphology (Figure1A) and expressed the cell surface marker Stro-1 (data not shown), confirming the presence of bone marrow stromal stem cells as described [35]. Treatment with 1:50 and 1:100 dilution of either Colloss or Colloss-E, but not with medium alone, induced characteristic morphological changes, starting at day 3 and becoming more obvious at day 7 . In general, cells became flattened and exhibited cytoplasmic projections suggestive of osteoblastic differentiation (Figre iA and not shown). This was accompanied by a marked decrease in total cell density (Figre1B) and cell proliferation (Figre1C).

Bovine \& equine BM Es induce osteoblastic differentiation of BMMSCS

To evaluate whether Colloss or C olloss-E induce osteoblastic differentiation of BM M SC s, treated cells were assessed for the presence of osteoblastspecific markers, such as alkaline phosphatase activity, osteopontin secretion and calcium deposits. Both Colloss and Colloss-E induced a sharp increase in alkaline phosphatase protein level at day 14 (Figure2A). This was accompanied by a significant increase in alkaline phosphatase enzyme activity in medium-free cell extracts at day 14 (Figre2B). Of note, Colloss and Colloss-E were devoid of alkaline phosphatase activity (data not shown). Furthermore, Colloss and Colloss-E upregulated both cellular (Figre3A) and secreted (Figre3B) osteopontin expression ( $p<0.01$ for Colloss, $p<0.05$ for Colloss-E). Most importantly, while untreated BMM SC S did not show any evidence of calcium deposits as detected by $\mathrm{H} \& \mathrm{E}$ stain, both Colloss- and Colloss-E-treated cells exhibited a significant number of calcium deposits (Figre $4 \mathbf{A} \& \mathbf{B}$ ) ( $p<0.05$ for Colloss and Colloss-E). Altogether, 
Figure 3. Colloss ${ }^{\circledR}$ and Colloss- $\mathrm{E}^{\circledR}$ induce osteopontin expression in BMMSCs.

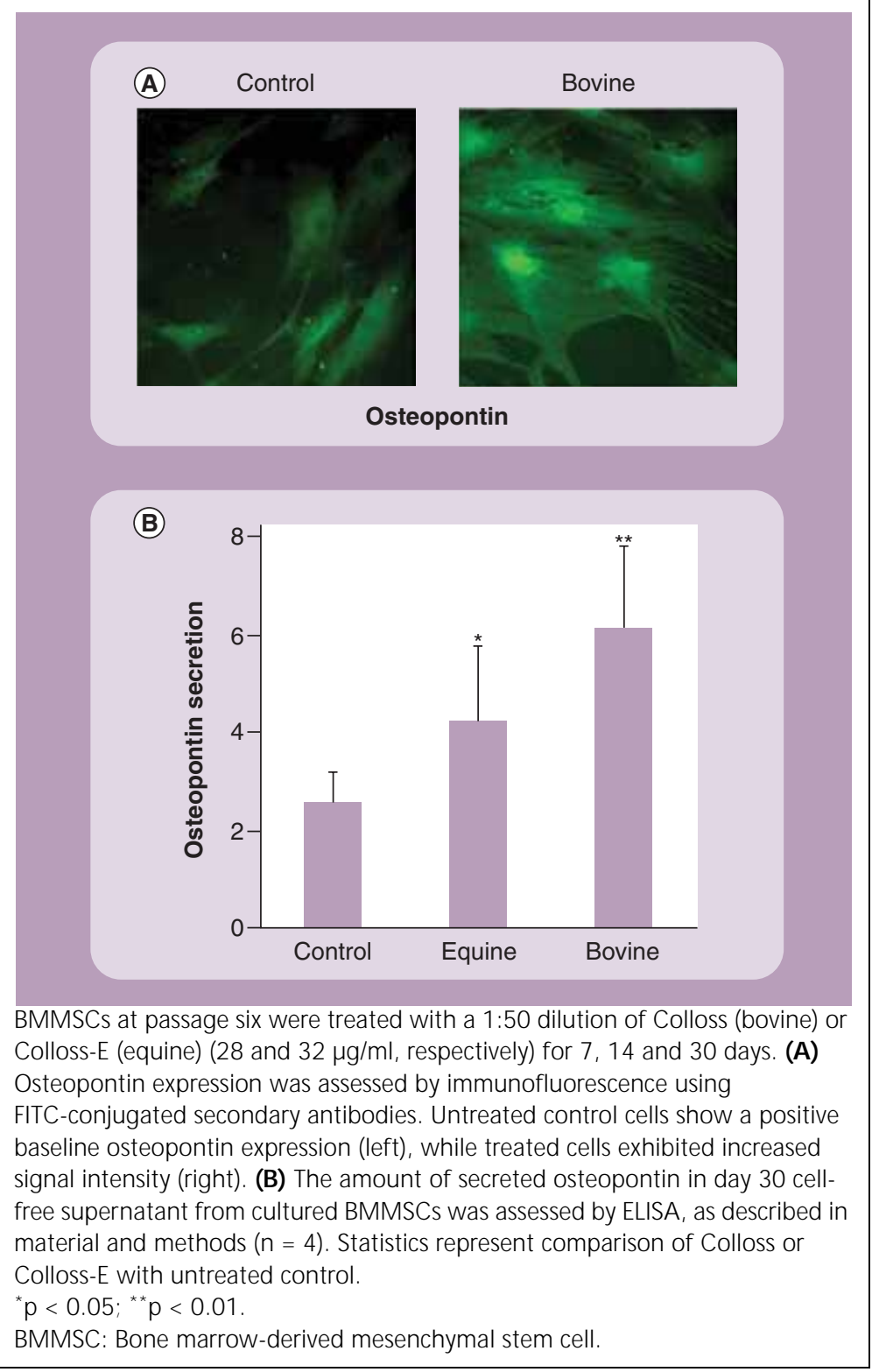

these results strongly suggest that both Colloss and Colloss-E induce osteoblastic differentiation of in vitro expanded BM M SCS.

\section{Colloss-E ${ }^{\circledR}$ contains osteogenic} growth factors

The fact that Colloss and Colloss-E induce osteoblastic differentiation of in vitro expanded BM M SC S suggests that these BMEs contain osteogenic growth factors, as reported for DBM [36]. Indeed, ELISA assays revealed that Colloss-E contains significant amounts of BMP-2 $(2.6 \pm 0.2 \mathrm{mg} / \mathrm{g})$, BM P-7 $(3.8 \pm 2.7 \mathrm{mg} / \mathrm{g})$, TGF- $\beta 1(55 \pm 11 \mathrm{mg} / \mathrm{g})$ and IG F-1 $(2.9 \pm 0.8 \mathrm{mg} / \mathrm{g})$ (Table1).

\section{Discussion}

In this report, we demonstrate that both xenogenic BM Es induce osteoblastic differentiation of in vitro-expanded BMMSCs. O ur findings have been corroborated with in vitro studies demonstrating the osteoinductive effect of D BM . Indeed, human D BM induced osteoblastic differentiation of a murine muscle-derived cell line [37] and, more importantly, of human bone marrow stromal cells [38]. Similarly, demineralized rabbit bone extracts increased the rate of osteoblastic differentiation of murine fibroblasts [39]. Furthermore, bovine bone extracts induced osteoblastic differentiation of rat mesenchymal cells with increased alkaline phosphatase activity and decreased proliferation [40]. A recent study explored the effects of Colloss on the human mesenchymal stem cell line that overexpresses human telomerase reverse transcriptase (TERT; hM SC-TERT), which maintains in vitro proliferation and osteoblastic differentiation potential [41]. In this study, Colloss had opposite effects depending on the differentiated state of the cells. Whereas, Colloss increased proliferation and decreased alkaline phosphatase activity of undifferentiated hM SC TERT cells, it diminished proliferation and increased alkaline phosphatase activity and collagen synthesis of osteoblastic differentiated hM SC-TERT cells [41]. H owever, our report is the first to demonstrate that Colloss and Colloss- $\mathrm{E}$ induce osteoblastic differentiation of in vitro-expanded human BM M SC S.

The mechanism of xenogenic BM E-induced osteoblastic differentiation of BMMSCS remains to be understood. $\mathrm{N}$ ormal in vivo cell differentiation is coordinated by both a structural scaffold and soluble cytokines, both provided by the microenvironment of target organs. The use of organ-specific extracts to supply stem cells with a milieu that mimics the in vivo microenvironment is an attractive alternative to the use of a defined combination of cytokines and growth factors. These extracts provide both the physical and biochemical signals in relative physiologic proportions. Indeed, xenogenic BM Es consist of collagens as well as noncollagenous-associated proteins. Here, we show that Colloss-E contains significant amounts of osteogenic growth factors, such as BM P-2, BM P-7, T GF- $\beta 1$ and IG F- 1 . Since the ELISA kits were optimized for human proteins, it is difficult to accurately assess the exact levels of growth factors in our extracts. Furthermore, since these cytokines were previously reported 


\section{Figure 4. Colloss ${ }^{\circledR}$ and Colloss- $\mathrm{E}^{\circledR}$ induce calcium deposition in BMMSCs.}

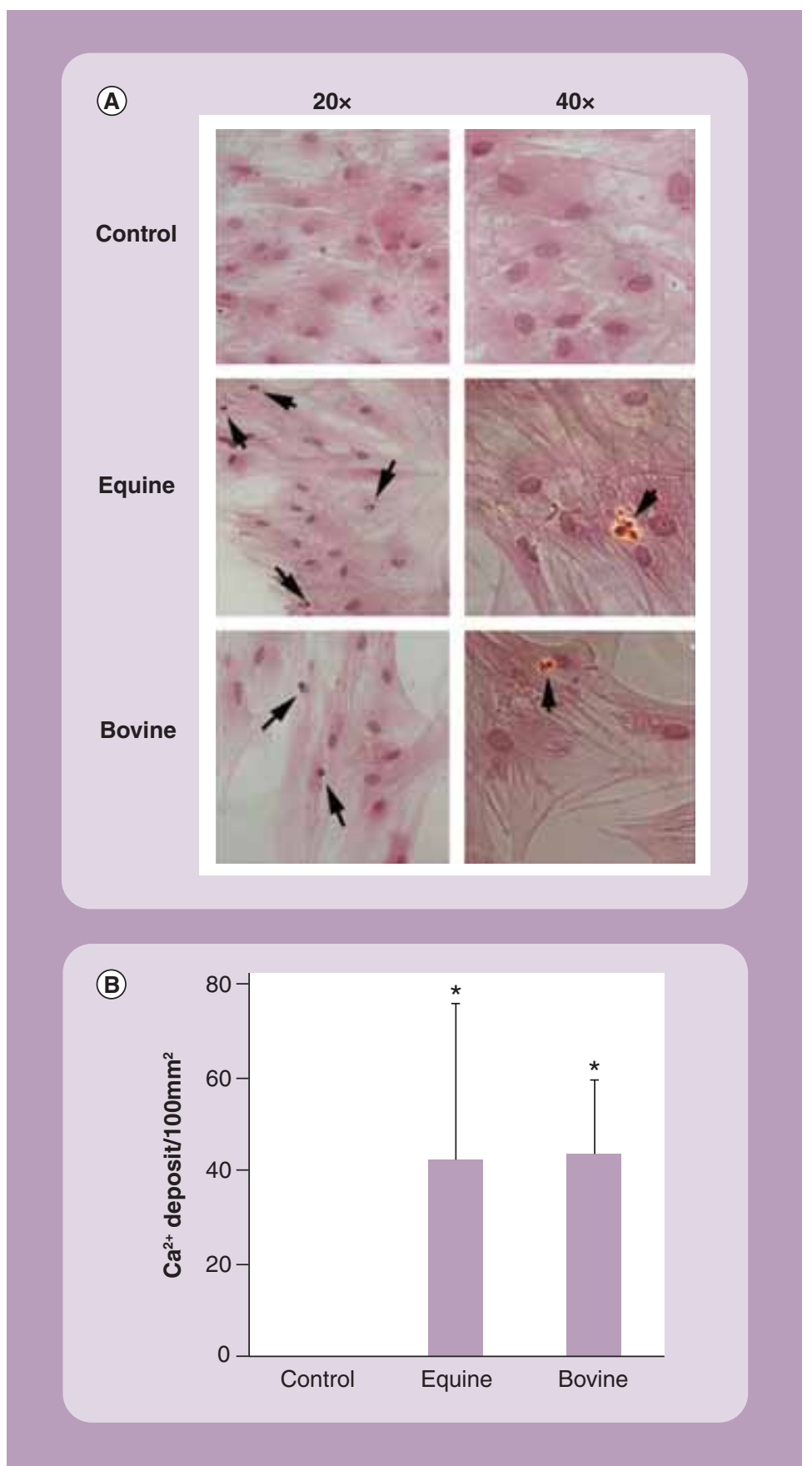

BM M SC at passage six were treated with a 1:50 dilution of Colloss (bovine) or Colloss-E (equine) (28 and $32 \mu \mathrm{g} / \mathrm{ml}$, respectively) for 15 days. (A) Calcium deposits were visualized at day 15 in H\&E-stained BM MSCs. (B) Quantification of calcium deposits was achieved by counting total calcium deposits on a coverslip and expressed as deposits $/ 100 \mathrm{~mm}^{2}$. ( $(\mathrm{n}=3)$. Statistics represent comparison of Colloss or Colloss-E to untreated control:

${ }^{*} p<0.05$.

BM MSC: Bone marrow-derived mesenchymal stem cell. to be osteogenic [36], their presence in Colloss-E probably contributes to the osteoblastic differentiation of BM M SC S. BM Ps induce osteoblast differentiation from nonosseous cells in vitro and ectopic bone formation in vivo, which suggest a direct effect of BM Ps on stem cells [12-15]. Similarly, Colloss-E enclosed in titanium mesh and implanted subcutaneously in rats induced bone formation [20]. H owever, although the role of collagen alone in osteoblastic differentiation in vitro, or osteoinduction in vivo, remains controversial [42], the collagen component in Colloss and Colloss-E could play an important role in attracting mesenchymal stem cells to the area of bone defect and in allowing exposure of stem cells to growth factors.

\section{Conclusion}

Finally, although the mechanism remains unknown, both Colloss and Colloss-E induce osteoblastic differentiation of in vitro expanded BM M SC S, which has far-reaching applications in the treatment of bone defects. These extracts can be co-administered with autologous BMMSC in the area of the bone defect, to enhance their osteoblastic differentiation. Alternatively, Colloss and Colloss-E can be used as an ex vivo tissue engineering scaffold to induce in vitro osteoblastic differentiation of expanded BM M SCs, which can then be applied in vivo. This provides a safe, inexpensive and readily available source of osteoinductive graft materials.

\section{Future perspective}

The use of organ-derived matrix extracts to induce the differentiation of stem cells will be the future of regenerative medicine since it provides cells with the best milieu for them to differentiate in a microenvironment that mimics their in vivo settings. This has vast ramifications since

\begin{tabular}{|c|c|}
\hline Growth factor & $\begin{array}{l}\text { Concentration } \\
(\mathrm{mg} / \mathrm{g})\end{array}$ \\
\hline BM P-2 & $2.6 \pm 0.2$ \\
\hline BM P-7 & $3.8 \pm 2.7$ \\
\hline TGF- $\beta 1$ & $55 \pm 11$ \\
\hline IGF 1 & $2.9 \pm 0.8$ \\
\hline
\end{tabular}

ELISA measurement of BMP-2, BMP-7, TGF- $\beta_{1}$ and IGF-1 in Colloss-E.

Concentration of growth factors is presented as mean $(n=7) \pm$ standard deviation. 
the use of autologous cells combined with an abundant and easily available matrix extract appears to be the most natural and cost-effective use for regenerative medicine.

\section{Disclosure}

El-Khoury and Hamdan-Khalil contributed equally to this work. Thiswork was supported by 'T he Bionic man' research grant from OSSACUR AG, Germany.

\section{Executive summary}

- In this study, we show that acellular collagen lyophilizates extracted from bovine or equine long bones (Colloss ${ }^{\circledR}$ and Colloss- ${ }^{\circledR}$ ) provide the necessary microenvironment to induce osteoblastic differentiation of in vitro expanded human bone marrow-derived mesenchymal stem cells.

- This finding has far-reaching applications in the treatment of bone defects.

- These extracts can be co-administered with autologous bone marrow-derived mesenchymal stem cells in the area of bone defect, to enhance their osteoblastic differentiation.

- Alternatively, Colloss and Colloss-E can be used as an ex vivo tissue-engineering scaffold to induce in vitro osteoblastic differentiation of expanded bone marrow-derived mesenchymal stem cells, which can then be applied in vivo.

- This provides a safe, inexpensive and readily available source of osteo inductive graft materials.

- Finally, this study forges new avenues in stem cell therapy based on the potential use of organ-derived extracts to induce organ-specific differentiation of mesenchymal stem cells.

Bibliography

1. Burchardt $\mathrm{H}$ : The biology of bone graft repair. Clin. Orthop. Relat. Res 174, 28-42 (1983).

2. Cutting $C B, M C C$ arthy JG, Berenstein A: Blood supply of the upper craniofacial skeleton: the search for composite calvarial bone flaps. Plast. Reconstr. Surg. 74(5), 603-610 (1984).

3. $H$ abal M B: D ifferent forms of bone grafts. In: Bone $G$ rafts and Bone Substitutes. $H$ abal M B, Reddi HD (Eds). Saunders, PA, USA 6-8 (1992).

4. Anderson D G, Albert TJ: Bone grafting, implants, and plating options for anterior cervical fusions. O rthop. Clin. N orth Am. 33(2), 317-328 (2002).

5. Finkemeier $C G$ : Bone-grafting and bone graft substitutes. J. Bone Joint Surg. Am. 84-A(3), 454-464 (2002).

6. U rist M R: A morphogenetic matrix for differentiation of bonetissue. Calcif. Tissue Res. (Suppl.) 98-101 (1970).

7. Tiedeman JJ, Garvin KL, Kile TA, Connolly JF: The role of a composite, demineralized bone matrix and bone marrow in the treatment of osseous defects. O rthopedics 18(12), 1153-1158 (1995).

8. Russell JL, Block JE: Clinical utility of demineralized bone matrix for osseous defects, arthrodesis, and reconstruction: impact of processing techniques and study methodology. O rthopedics 22(5), 524-531 (1999).
9. Mulliken JB, G lowacki J, Kaban LB, Folkman J, M urray JE: U se of demineralized allogeneic bone implants for the correction of maxillocraniofacial deformities. Ann. Surg. 194(3), 366-372 (1981).

10. H an B, Tang B, N imni M E: Q uantitative and sensitive in vitro assay for osteoinductive activity of demineralized bone matrix. J. O rthop. Res. 21(4), 648-654 (2003).

11. Cammisa FP Jr, Lowery G, Garfin SR et al.: Two-year fusion rate equivalency between Grafton DBM gel and autograft in posterolateral spine fusion: a prospective controlled trial employing a side-by-side comparison in the same patient. Spine 29(6), 660-666 (2004).

12. Wozney J M, Rosen V, Celeste AJ et al.: $N$ ovel regulators of bone formation: molecular clones and activities. Science 242(4885), 1528-1534 (1988).

13. Vehof JW, de Ruijter $A E$, Spauwen $P H$, Jansen JA: Influence of rhBM P-2 on rat bone marrow stromal cells cultured on titanium fiber mesh. Tissue Eng. 7(4), 373-383 (2001).

14. Vehof JW, Takita H, Kuboki Y, Spauwen $\mathrm{PH}$, Jansen JA: H istological characterization of the early stages of bone morphogenetic protein-induced osteogenesis. J. Biomed. M ater. Res. 61(3), 440-449 (2002).

15. Vehof JW, van den D older J, de Ruijter JE, Spauwen PH , Jansen JA: Bone formation in $\mathrm{C}$ aP-coated and noncoated titanium fiber mesh. J. Biomed. M ater. Res A 64(3), 417-426 (2003).
16. Block JE, Poser J: D oes xenogeneic demineralized bone matrix have clinical utility as a bone graft substitute? $\mathrm{M}$ ed. $H$ ypotheses 45(1), 27-32 (1995).

17. Bertagnoli R: 0 steoinductive bone regeneration substance Colloss in spinal fusion. Eur. Spine J. 11, 189-190 (2002).

18. Schlegel KA, Kloss FR, Kessler $P$, Schultze-M osgau S, N kenke E, W iltfang $\mathrm{J}$ : Bone conditioning to enhance implant osseointegration: an experimental study in pigs. Int. J. O ral M axillofac. Implants 18(4), 505-511 (2003).

19. Wiltfang J, Kloss FR, K essler $P$ et al.: Effects of platelet-rich plasma on bone healing in combination with autogenous bone and bone substitutes in critical-size defects. An animal experiment. Clin. O ral Implants Res. 15(2), 187-193 (2004).

20. Kloss FR, Schlegel KA, Felszeghy E, Falk S, W iltfang J: Applying an osteoinductive protein complex for regeneration of osseous defects. M und. Ki efer. Gesichtschir. 8(1), 12-17 (2004).

21. Li H, Zou X, Woo C, Ding M, Lind $M$, Bunger $C$ : Experimental anterior lumbar interbody fusion with an osteoinductive bovine bone collagen extract. Spine 30(8), 890-896 (2005).

22. Walboomers XF, Jansen JA: Bone tissue induction, using a CO LLOSS-filled titanium fibre mesh-scaffolding material. Biomaterials 26(23), 4779-4785 (2005).

23. Boden $\mathrm{S}, \mathrm{U}$ gbo $\mathrm{J} \mathrm{L}$, O liver $\mathrm{C}$, Briest $\mathrm{A}$ : $O$ sseogenetic collagen complex as an effective graft alternative in experimental 
posterolateral lumbar spine arthrodesis. Eur. Cell. M ater. 10(Suppl. 3), 51 (2005).

24. Lasmezas $\mathrm{Cl}$ : The transmissible spongiform encephalopathies. Rev. Sci. Tech. 22(1), 23-36 (2003).

25. WilliamsES, M iller M W: Transmissible spongiform encephalopathies in nondomestic animals: origin, transmission and risk factors. Rev. Sci. Tech. 22(1), 145-156 (2003).

26. Schlegel KA, D onath $K$, Rupprecht $S$ et al.: $D$ enovo bone formation using bovine collagen and platelet-rich plasma. Biomaterials 25(23), 5387-5393 (2004).

27. N ienhuijs M E, Walboomers XF, M erkx M A, Stoelinga PJ, Jansen JA: Bonelike tissue formation using an equine CO LLOSS Efilled titanium scaffolding material. Biomaterials 27(16), 3109-3114 (2006).

28. H uffer WE, Benedict JJ, Rettenmaier R, Briest A: O steoinduction with CO LLOSS, COLLOSSE, and GFm. Adv. Exp. Med. Biol. 585, 87-100 (2006).

29. Baksh D, Song L, Tuan RS: Adult mesenchymal stem cells: characterization, differentiation, and application in cell and gene therapy. J. Cell. M ol. M ed. 8, 301-316 (2004).
30. Song L, Baksh D, Tuan RS: M esenchymal stem cell-based cartilage tissue engineering: cells, scaffold and biology. Cytotherapy 6(6), 596-601 (2004).

31. Kassem M. M esenchymal stem cells: biological characteristics and potential clinical applications. Cloning Stem Cells 6(4), 369-374 (2004).

32. Shin H, Temenoff JS, Bowden GC et al.: $O$ steogenic differentiation of rat bone marrow stromal cells cultured on Arg-G lyAsp modified hydrogels without dexamethasone and beta-glycerol phosphate. Biomaterials 26(17), 3645-3654 (2005).

33. Block JE: The role and effectiveness of bone marrow in osseous regeneration. $M$ ed. H ypotheses 65(4), 740-747 (2005).

34. O reffo RO, D riessensFC, Planell JA, Triffitt JT: Growth and differentiation of human bone marrow osteoprogenitors on novel calcium phosphate cements. Biomaterials 19(20), 1845-1854 (1998).

35. Simmons PJ, Torok-Storb B: Identification of stromal cell precursors in human bone marrow by a novel monoclonal antibody, ST RO -1. Blood 78(1), 55-62 (1991).

36. Bae H W, Zhao L, Kanim LE, Wong $P$, D elamarter RB, D awson EG : Intervariability and intravariability of bone morphogenetic proteins in commercially available demineralized bone matrix products. Spine 31(12), 1299-1306 (2006).
37. Peel SA, H u ZM, Clokie CM : In search of the ideal bone morphogenetic protein delivery system: in vitro studies on demineralized bone matrix, purified, and recombinant bone morphogenetic protein. J. Craniofac. Surg. 14(3), 284-291 (2003).

38. Kasten $P$, Luginbuhl $R$, van Griensven $M$ et al.: Comparison of human bone marrow stromal cells seeded on calcium-deficient hydroxyapatite, $\beta$-tricalcium phosphate and demineralized bone matrix. Biomaterials 24(15), 2593-2603 (2003).

39. Torricelli P, Fini M, Giavaresi G, Giardino R: In vitro osteoinduction of demineralized bone. Artif. Cells Blood Substit. Immobil. Biotechnol. 26(3), 309-315 (1998).

40. Joos UE, Fehrenbach E, H ogh-Janovsky K, Wimmer FM, Schneider EM, Schmidt KH : Effects of a new boneinducing biomaterial on mesenchymal cells in vitro. Artif. Organs 16(4), 354-360 (1992).

41. Woo C, Li H, Baatrup A et al.: Effects of bone protein extract on human mesenchymal stem cells proliferation and differentiation. J. Biomed. M ater. Res A 79(3), 552-556 (2006).

42. Yang C, H illas PJ, Baez JA et al.: The application of recombinant human collagen in tissue engineering. BioD rugs 18 (2), 103-119 (2004). 